\title{
LATINOS Y ANGLOSAJONES. EL 98 EN EL FIN DE SIGLO SUDAMERICANO :
}

por

\section{MÓNICA QULADA}

Centro de Estudios Históricos (C.S.I.C.)

RESUMEN: En este articulo se estudian las reacciones -oficiales y oficiosas- de los países de América de Sur ante la guerra hispano-norteamericana, y se revisan las interpretaciones existentes sobre la proyección del 98 en el imaginario colectivo de esas poblaciones mediante el análisis del clima de ideas en cuyo contexto se produjo la guerra y de los procesos ideológicos y simbolicos a ella asociados. Se estudia en particular la visión de la guerra como el enfrentamiento entre dos "razas" rivales y opuestas - Latinos y Anglosajones-, y se sostiene que ello dio lugar en América del Sur a una reformulación simbólica acerca de la capacidad intrínseca del elemento hispanico para generar un modelo de progreso.

Palabras Clave. Edad contemporánea, relaclones internacionales, historia de Ideas, raza, progreso, civilización.

ABSTRACT: This article studies the reactions of the South American countries vis-à-vis the Spanish American War, both at the official and non-official level. Also the existing views about the projection of the "98" on the South American collective representations are revisited, through the analysis of the ideological environment that contextualized the war and the associated ideological and symbolical processes. It is argued here that the visualization of the war as the confrontation between two different and rival races -Latins and Anglosaxons - opened the way in South America to the reformulation of the Hispanic potentialities for progress.

KEY WORDS: Modern history, international relations, history of ideas, race, progress, civilization.

\footnotetext{
1 Esta investigación fue realizada en el marco del proyecto $91-0003$ «El contexto internacional del 98 espartol», financiado por la DIGICYT. Quiero expresar mi agradecimiento a dos personas con las
} 
A cien años de los sucesos del 98, la historiografía no ha producido aún un análisis global sobre la incidencia y las repercusiones de este evento en la América del Sur: Ni siquiera los estudios y monografías que se ocupan de la política exterior de los estados sudamericanos en los años del fin de siglo le dedican espacio a la contienda. Pero, mientras que las actuaciones oficiales y oficiosas de esos países con respecto a la guerra hispano-norteamericana no han sido objeto de estudio hasta hoy, en infinidad de trabajos de historia general aparece en cambio, de forma recurrente, una afirmación que hace referencia al 98. Dicha afirmación, expuesta generalmente en términos escuetos y de manera casi axiomática, atribuye a ese evento el carácter de divisoria de aguas que, al resolverse con la pérdida definitiva de los territorios americanos por parte de España, habría modificado la imagen de este país en sus antiguas colonias, poniendo fin a los miedos y las suspicacias que habían jalonado las décadas posteriores a la independencia. Esto se complementa con una doble interpretación, que atribuye a la influencia del 98 en Hispanoamérica el surgimiento de una percepción negativa de los Estados Unidos y la potenciación de las corrientes hispanoamericanistas vinculadas a la revalorización de la antigua metrópoli ${ }^{2}$.

De tal manera, por un lado existe un virtual vacío de conocimiento sobre la recepción -oficial y oficiosa- de la guerra hispano-norteamericana en los países de América del Sur; por otro, el 98 forma parte de un conjunto de interpretaciones que afectan al nivel del imaginario; es decir, ese ámbito de representaciones colectivas cuya realidad especifica reside en su propia existencia, en el impacto múltiple y variable que ejerce sobre las mentalidades y los comportamientos sociales ${ }^{3}$.

Considero que el conocimiento de la recepción de la guerra hispano-norteamericana en los países de América del Sur y del clima de ideas en cuyo contexto se produjo puede contribuir, no sólo a paliar ese vacío de la historiografía, sino a matizar y revisar las interpretaciones existentes sobre la proyección del 98 en el imaginario colectivo sudamericano. Con ese fin, en las páginas que siguen procuraré estudiar las reacciones que suscitó la guerra hispano-norteamericana y analizar de qué manera y en qué medida los procesos ideológicos y simbólicos a ella asociados se articularon en algunas preocupaciones y perspectivas propias del fin de siglo.

\section{pocas nUEces, pero mucho ruido}

Al declararse las hostilidades, todos los gobiernos sudamericanos (e hispanoamericanos en general) asumieron una misma postura de neutralidad ante

que este trabajo tiene una especial deuda de gratitud: el Dr. Luis Alvarez, Investigador Principal del proyecto mencionado, y la licenciada Silvina Montenegro, de la Universidad de Buenos Aires, cuya colaboración fue inestimable para reunir una parte de los materiales que han hecho posible este análisis.

2 Aunque esta interpretación afecta a todos los países hispanoamericanos, en el presente articulo nos centraremos en los procesos propios del área austral del continente.

3 BaCkzo, Bronislaw: Les imaginaires sociaux, Payot, Paris, 1984, pág. 8.

Hispania, LVI1/2, núm. 196 (1997) 589-609 
el conflicto. Esa toma de posición estuvo condicionada por tres polos de tensión: a) el hecho independentista, que esos países no podían mirar sino con simpatía; b) el intervencionismo de la gran potencia regional, que confirmaba y acentuaba temores preexistentes, y c) la percepción de que los sucesos del 98 afectarian al equilibrio internacional de poderes.

Este último tema era particularmente espinoso, ya que se asociaba a una de las grandes preocupaciones finiseculares: la defensa de la soberanía territorial. No es ocioso recordar que en las décadas anteriores a la guerra hispano-norteamericana, América del Sur había sufrido conflictos tan graves en cuanto a modificación de fronteras y acusaciones de expansionismo como la Guerra del Pacífico o la Guerra del Paraguay. Y también, que en 1898 Argentina y Chile estaban dirimiendo, sin intervención de sus ejércitos pero con mucho encono y apasionamiento verbal y diplomático, el problema de la delimitación de su frontera andina. Por ello, a finales del siglo xIX y desde la perspectiva de los países del cono sur, la preocupación por el equilibrio internacional de poderes implicaba no sólo el temor al expansionismo norteamericano, sino cuestiones globales de geopolítica y de derecho internacional, tales como la definición misma de las fronteras, la legitimación de su trazado y, sobre todo, las garantías de inviolabilidad del espacio territorial.

En ese contexto, las relaciones con la antigua metrópoli ocupaban un espacio exiguo en la agenda exterior de los países sudamericanos. La España finisecular ofrecía un interés casi nulo para las aspiraciones políticas o económicas de los gobiernos sudamericanos, lo que determinaba más aún que la desconfianza hacia posibles "rebrotes imperiales»- la escasa fluidez de los intercambios. Si a ello se agrega la brevedad extrema de la guerra (menos de tres meses, lo que no dio tiempo a que se generaran cambios de posición), se comprende que las tensiones antes mencionadas limitaran la postura de todos los gobiernos sudamericanos al mantenimiento de una política de prescindencia; política cuya unanimidad sólo se rompía en los matices.

En un extremo aparecen las autoridades argentinas, que hicieron gala de una notable indiferencia ante el conflicto hispano-norteamericano y concentraron su atención en problemas mucho más acuciantes. Ejemplo significativo de ello es la sesión del 9 de mayo de 1898 en el Congreso de los Diputados. En ella, la aprobación de la neutralidad oficial ante la guerra se hizo sin que mediara ningún tipo de debate. Lo que contrasta vivamente con la ansiedad mostrada por los legisladores ante la situación de la frontera con Chile, que ese mismo día suscitó una agitada polémica acerca de la reorganización de las fuerzas armadas y militares solicitada por varios congresistas para hacer frente a un posible conflicto con el país vecino ${ }^{4}$. A su vez, esa misma preocupación por el litigio de la frontera andina confirió un leve matiz pro-norteamericano a la neutralidad oficial declarada por el gobiemo chileno, que se

4 Barrington a Salisbury, Buenos Aires, 11 de mayo de 1898, Foreign Office FO/118/243/48. 
hallaba interesado en garantizar el apoyo estadounidense a la posición de Santiago en dicho conflicto de límites s.

El extremo opuesto a esas posturas se encuentra en la actitud del gobiemo venezolano, que pidió disculpas al representante español en Caracas -y sólo a él- por la declaración pública de neutralidad ante la guerra. A diferencia de los restantes países de la región -que hicieron sus declaraciones oficiales entre la última semana de abril y la primera de mayo- el gobierno venezolano demoró la suya hasta junio, en un intento por eludir las tensiones suscitadas por las presiones de una opinión pública proespañola, de un lado, y el sacro temor a potenciales represalias por parte de los Estados Unidos, de otro ${ }^{6}$. Represalias que, por otra parte, las delegaciones de este último país se ocuparon en muchos casos de agitar amenazadoramente. Hubo episodios particularmente hostiles, como la violenta reacción norteamericana ante el rumor (que se demostró falso) de que el gobierno chileno pensaba vender su barco de guerra $O^{\prime} H i g g i n s$ a España, lo que produjo una situación de tirantez diplomática ${ }^{7}$. Y no faltaron incidentes tragicómicos, como la situación embarazosa que generó el representante de los Estados Unidos en Caracas, al exigir a las autoridades la retirada del exequatur al cónsul de España en Ciudad Bolivar ${ }^{8}$.

En algunos países, el temor a las reacciones norteamericanas llevó a extremar la voluntad de prescindencia. Es el caso del Uruguay, cuyo gobierno ordenó la censura sobre todo tipo de manifestaciones públicas en torno a la guerra. El afán por imponer una neutralidad estricta se tradujo en dos decretos hechos públicos en el mes de abril: el primero prohibía las manifestaciones en favor de cualquiera de los beligerantes, en tanto que por el segundo los oficiales del ejército quedaban impedidos de acudir a mítines organizados por uno $u$ otro de los contendientes. El 12 de mayo las autoridades impedían la formación de una Sociedad de Cruz Roja Sudamericana con el pretexto de

5 Gosling a Salisbury, Santiago de Chile, 26 de abril de 1898, FO/132/55. Las posiciones chilenas en el litigio con Argentina contaron efectivamente con el apoyo de Washington. Poco tiempo después de la guerra hispano-norteamericana el representante de Washington en Santiago llegó a sugerir al Ministro de Relaciones Exteriores la ruptura de relaciones con su vecino trasandino. Gosling a Salisbury, Santiago de Chile, 20 de septiembre de 1898, FO/118/243/252.

6 Haggard a Salisbury, Caracas, 7 de junio de 1898 , FO/185/866.

7 El Departamento de Estado norteamericano exigió a la Cancillería chilena una negación de intenciones, que debía ser entregada por escrito y de forma uperentoria». Esta demanda fue considerada «diçatorial» por el miniștro chileno, quien envió a Washington una nota redactada «in the coldest terms, pointing out that Chile was quite aware of her duties as a neutral Power, of which there was no need to remind hens. Gosling a Salisbury, Santiago de Chile, 27 de junio de 1898, $\mathrm{FO} / 115 / 1077$

${ }^{8}$ La exigencia norteamericana se debió a la información de que alrededor de 1.000 voluntarios habían sido enrolados por la representación española en Caracas. Haggard a Salisbury, Caracas, 7 de junio de 1898, FO/185/866. La actitud autoritaria del delegado de los Estados Unidos, la confusión puesta de manifiesto por el gobiemo venezolano y el intercambio de irónicos comentarios entre los representantes de Washington y Londres proporcionan un panorama muy expresivo de fa diplomacia finișecular.

Hispania, LVI/2, núm. 196 (1997) 589-609 
que dicha asociación pretendía asistir exclusivamente a España, «lo que violaría los principios de la neutralidad». También fue suspendida una obra de teatro, aduciéndose que contenía alusiones ofensivas hacia los Estados Unidos. No es ocioso consignar que -como suele suceder en estos casos- todas las medidas de censura se demostraron completamente ineficaces para acallar a la opinión pública ${ }^{9}$.

Como se desprende de los párrafos anteriores, la voluntad de prescindencia puesta de manifiesto en los niveles oficiales no tuvo correlato en la opinión pública. Por el contrario, las tensiones mencionadas al comienzo de este apartado contribuyeron a convertir en un debate de contenidos muy complejos e incluso contradictorios- lo que de otra manera se hubiera limitado a un apoyo irrestricto y sin matices a la independencia cubana. En efecto, la opinión pública, tradicionalmente hostil a la madre patria en su contencioso con Cuba, se volcó a una simpatía generalizada por la causa española a partir de la declaración nortearnericana de hostilidades, redactada en unos términos que resultaron ofensivos también para muchos hispanoamericanos ${ }^{10}$. Una consecuencia de esta reacción fue la movilización afectiva y solidaria de una parte de la población en favor de España; movilización que en países como Argentina, Chile o Uruguay fue bastante importante y prefigura la que se produciría en mucha mayor escala cuarenta años más tarde, cuando llegaran los ecos de la guerra civil española.

Lo mismo que en el 36, en el 98 numerosas personas se agolparon ante los consulados españoles de Buenos Aires, Montevideo, Santiago de Chile o Río de Janeiro, y también de otras ciudades alejadas de las capitales, para solicitar su traslado como voluntarios al frente. En Montevideo, mientras que el gobierno se esforzaba por impedir todo tipo de manifestación partidista, no menos de 20 oficiales del ejército y la marina pedían la baja para poder ofrecer sus servicios a España ${ }^{1}$. Y las suscripciones públicas para enviar dinero a la peninsula fueron notables en cantidad y resultados. Curiosamente, si en

- Baring a Salisbury, Montevideo, 27 de abril y 13 de mayo de 1898, FO/505/264.

10 Como observaba el representante británico en Santiago de Chile, «... although the Spanish Administration in Cuba and the means adopted for the suppression of the rebellion in that Island are generally disapproved (...), the high-handed vulgarity and bluster displayed by the War Party at Washingtohn are loudly condemned, as is also the unnecessary offensive language of the ultimatums. Gosling a Salisbury, 21 de abril de 1898, FO/132/55.

"Entre ellos el conocido general Fortunato Flores, quien afirmó además públicamente que del Río de la Plata podrían salir 4 ó 5 mil hombres para defender con las armas a la madre patria. Esta manifestación, hecha ante una concurrida reunión de residentes espanioles, parece haber provocado la promulgación de los decretos de censura antés mencionados. El gobierno español, por su parte, declinó el ofrecimiento de los militares uruguayos, «por oponerse a ello la ley constitutiva de nuestro Ejérciton. La Nación, Buenos Aires, 26, 27 y 29 de abril de 1898; Baring a Salisbury, Montevideo, 26 de abril de 1898, FO/115/1076. En la Argentina, una figura pública de tanta relevancia como el militar y escritor Lucio V. Mansilla — que a la sazón ocupaba un cargo diplomático de su país en Francia - anunció un deseo semejante de «poner su espada al servicio de Españas. Ver en El Correo Español, Buenos Aires, 31 de mayo de 1898, la transcripción de la entrevista publicada en La France Militaire, París.

Hicp, *t LVII/2, núm. 196 (1997) 589-609 
el 36 con las colectas se compraban y enviaban ambulancias, en el 98 los partidarios de España en Buenos Aires, por ejemplo, parece que consiguieron dotar un barco por suscripción popular, aunque la brevedad de la guerra impidió que pudiera ser útil a sus destinatarios ${ }^{12}$.

Si las manifestaciones en favor de España y los actos de solidaridad con ella surgen con toda claridad de la prensa y la documentación de la época, más difícil es definir la extracción social de los donantes y de los que se implicaron afectivamente en la guerra. No obstante, hay testimonios llamativos que parecen indicar que, junto a miembros de las élites intelectuales y políticas o de grupos importantes de comerciantes, asoma la presencia de otros sectores menos favorecidos. No podría hablarse, claro está, de clase obrera, pero sí posiblemente de sectores artesanales. Por ejemplo, el representante británico en Montevideo, con ocasión de una de estas suscripciones públicas, se asombraba por la generosidad, según él "notable», que habían mostrado las "clases inferiores" ${ }^{13}$. Y una crónica periodística sobre uno de estos actos en Buenos Aires informaba que se había reunido una multitud de más de 8.000 personas, en la que se confundían «el rico comerciante y el humilde menestral; el hombre de levita y el hombre de blusa" ${ }^{14}$. Parecería entonces que la guerra hispano-norteamericana tuvo proyección en un ámbito de sociabilidad pública bastante amplio, que trascendió los límites estrictos de las élites.

En parte, esta proyección se explica por el hecho de que esos países contaban con numerosos contingentes de inmigración española que tenían una incidencia importante en los sectores artesanales y de servicios, particularmente en el comercio minorista. Lo mismo que en 1936, los actos de solidaridad se verían favorecidos por esa presencia ${ }^{15}$. Asimismo, en el debate público que se produjo en torno a la guerra hispano-norteamericana no debe subvalorarse la intervención de numerosos intelectuales e ideólogos españoles, afincados en los países de América del Sur como resultado de los exilios sucesivos provocados por las luchas políticas en la península, en particular el relacionado con los avatares en torno a la I República ${ }^{16}$. Internamente divididos en tendencias conservadoras y liberales, ejercían una eficaz labor publi-

12 Las acciones de solidaridad con España que la guerra hispano-norteamericana generó en los paises del cono sur pueden seguirse con toda facilidad en la prensa de las principales capitales, especialmente a lo largo de abril y mayo de 1898.

13 Baring a Salisbury, Montevideo, 26 de abril de 1898, FO/115/1076.

14 La Nación, Buenos Aires, 24 de abril de 1898.

15 Además de la recaudación de fondos y ofrecimientos de voluntarios para ir a luchar al frente, se dieron también casos extremos de solidaridad con España como el anuncio de un complot de residentes españoles en Valparaíso (Chile) para volar el buque norteamericano Marietta, fondeado en ese puerto. La conspiración, de la cual fue informado el representante de los Estados Unidos en Santiago, fue frustrada por intervención de las autoridades chilenas. Gosling a Salisbury, Santiago de Chile, 11 de abril de 1898 , FO/115/1076.

16 BIAGINi, Héctor: Intelectuales y politicos españoles a comienzos de la inmigración masiva. Centro Editor de América Latina, Biblioteca Política Argentina, Buenos Aires, 1995. Esta obra es representativa de una línea de investigación que en los últimos tiempos está revisando y desmontando

Hispania, LVII/2, núm. 196 (1997) 589-609 
cística y pedagógica sobre el medio local a través de la fundación y dirección de publicaciones periódicas, así como la edición y traducción de libros ${ }^{17}$.

En los medios liberales de este sector ilustrado de la colonia española se manifiesta con toda claridad tanto la consternación que produjo la intervención norteamericana como las complicadas justificaciones ideológicas para legitimar el cambio, de la noche a la mañana, desde la condena de la «España oscurantista» al deseo de victoria de la «España eterna»; sin ceder ni un ápice, al mismo tiempo, en la defensa a ultranza del derecho de Cuba a su independencia. Tal cambio de opinión - que en lo referente a la defensa de España les acercaba por primera vez a sus enemigos conservadores-era explicado como fiuto de su «preferencia innata por la Madre Patria cuando está enfrentada a miembros de la raza anglosajona: ${ }^{18}$. Esta última expresión, repetida hasta la saciedad dentro y fuera de la colonia hispana, estaba muy lejos de ser anecdótica.

En efecto, para comprender en todos sus matices la repercusión pública de los sucesos del 98, no basta tener en cuenta los temores por el reforzamiento del poder norteamericano que suscitó la intervención de este país en el conflicto entre España y Cuba, ni tampoco la potenciación de las reacciones en torno a la guerra a que indujo la presencia española en tierras sudamericanas. Es necesario hacer referencia, asimismo, al clima de ideas en que esos sucesos se inscribieron y al tipo de discurso que articuló las posiciones y las expectativas en torno a la contienda.

Desde esta perspectiva, el contraste con los sucesos de 1936 no puede ser mayor. Si en esta última fecha ${ }^{19}$ el debate ideológico y los llamamientos a las

algunos de los tópicos más enraizados sobre los intercambios entre España y sus antiguas colonias durante el siglo XIX, tales como la atribución en bloque de «incultura» e incluso analfabetismo a los contingentes inmigratorios peninsulares que arribaron a las costas americanas en la segunda mitad del siglo XIX; o la inexistencia de influencias españolas de orden liberal y progresista en los procesos ideológicos hispanoamericanos. Sobre esto último véase también LÓPEZ OCóN, Leoncio: Biografia de "La América*, Una crónica hispano-americana del liberalismo democrático español (1857-1886), CSIC, Colección Tierra Nueva e Cielo Nuevo, Madrid, 1987; íd: «Mensajeros de la ciencia en la periferia. La divulgación de los conocimientos científico-técnicos en la América Latina durante el siglo XIX a través de la prensa», Región, 5, Cali (Colombia) marzo de 1996, págs. 3-33.

17 La incidencia de estos intelectuales en los procesos ideológicos y políticos de sus países de adopción todavia no ha sido suficientemente aquilatada, pero hay indicios para suponer que, en términos relativos a las condiciones propias de la época, pudo haber sido superior incluso a la ejercida por los «transterrados» de la guerra civil cuarenta años más tarde. En Buenos Aires, por ejemplo, hacia finales del siglo xIX existian alrededor de cincuenta publicaciones periódicas editadas por españoles. Véase BIAGINI, ob.cit. Asimismo, muchos de los medios de prensa caracteristicamente liberales de la segunda mitad del siglo x।X —omo El Vigía, de Bogotá, o Don Quijote de Buenos Aires - fueron fundados y dirigidos por españoles exiliados.

18 El Vigia, Bogotá, 27 de abril de 1898.

19 Sobre las repercusiones de la guerra civil española en América Latina, el tector interesado puede consultar FalCOFF, Mark y PIKE, Frederick: The Spanish Civil War 1936-1939. American Hemispheric Perspectives, University of Nebraska Press, Lincoln \& London, 1982, y QUiJaDA, Mónica: Aires de República, aires de Cruzada. La guerra civil española en la Argentina. Editorial Sendai, Barcelona, 1991, entre otros. 
movilizaciones iban a expresarse en términos de lucha de clases, de polarización entre derechas e izquierdas, o entre fascismo y liberalismo, lo que caracteriza al discurso que se produjo en torno a la guerra del 98 es que no aparecen en él referencias a la lucha de clases, ni contenidos ideológicos asociados a determinados partidos políticos. Lo que hay es una racialización extrema de las dicotomías: tanto en América como en Europa, el conflicto serfa visto en términos del combate entre dos «razas» consideradas antitéticas: la latina y la anglosajona.

Es importante detenerse en esta conceptualización por dos razones. Primero, porque es dudoso que sin esta visión racializada de la guerra se hubiese producido la alineación afectiva junto a España de prácticamente toda la América del Sur, incluidos los sectores liberales y tradicionalmente antihispánicos. Segundo, porque esa alineación mayoritaria desplazó los términos del debate al seno mismo de la dicotomía racial. En otras palabras, en las discusiones no se expresaba el enfrentamiento entre quienes ansiaban la victoria de uno u otro de los contendientes, ya que es difícil encontrar testimonios donde se manifieste el deseo de que triunfen los Estados Unidos. El eje de la discusión, por el contrario, consistía en aquilatar las posibilidades de cada una de las dos "razas» contendientes, no sólo para alzarse con la victoria en la guerra, sino para proseguir y/o liderar el camino de la civilización.

\section{LATINOS Y ANGLOSAJONES}

La expresión del conflicto en términos de un enfrentamiento entre latinos y anglosajones tuvo una gran capacidad de convocatoria, lo que se pone de manifiesto en la forma recurrente con que se apeló a la adefensa de la latinidad" en la mayoría de los llamamientos a los actos públicos y las suscripciones populares. Ejemplo de ello -entre otros muchos posibles- es el acto del 2 de mayo celebrado en el Teatro Victoria de Buenos Aires con la doble finalidad de repudiar la intervención norteamericana y suscribir fondos de ayuda a España. Este acto público, que según la prensa de la época tuvo una asistencia multitudinaria, hizo su llamamiento a partir de un programa que se iniciaba con la ejecución del himno nacional argentino, seguido por la Marsellesa, las Marchas Reales respectivas de Italia y España, el preludio de «La Dolores" y la Marcha de Cádiz. En ese mismo programa, los discursos del ex presidente argentino Roque Sáenz Peña y del historiador francés afincado en el Plata, Paul Groussac, se completaban con unos versos compuestos y leídos por el Cónsul italiano que llevaban por título: «Per la Spagna, canzone di guerra», y cantaban a España como heredera de la grandeza de Roma ${ }^{20}$.

La facilidad con que la opinión pública incorporó esta visión racializada de la guerra se debe a que la contraposición entre latinos y anglosajones

20 La crónica completa de este evento puede seguirse en El Correo Español, Buenos Aires, 3 y 4 de mayo de 1898.

Hispania, LVLI/2, nüm. 196 (1997) 589-609 
estaba muy lejos de ser nueva. Por el contrario, se inscribía en el afán clasificador de la diversidad humana que, desde la centuria anterior, venía estableciendo escalas jerárquicas entre las "razas» y consagrando la superioridad del hombre blanco o "caucásicon con respecto a sus congéneres de piel más oscura.

A mediados del siglo xIX, el pensamiento racial introdujo un nuevo desarrollo técnico que habría de tener importantes consecuencias ideológicas. Se trataba de la medición del índice cefálico ${ }^{21}$, que fue utilizada fundamentalmente para medir las diferencias entre las poblaciones europeas, consideradas hasta entonces por la raciología como un conjunto unitario. La conjunción de estos desarrollos "científicos» acerca de la diversidad "física" de los europeos con otras tendencias previas vinculadas generalmente al movimiento romántico (como la que resaltaba la superioridad de las instituciones anglosajonas con respecto a las originadas en otras regiones de ese continente) tuvo una consecuencia importante: la historia europea y las tensiones polfticas contemporáneas serían crecientemente interpretadas como el resultado de la lucha entre las diferentes "razas" de Europa ${ }^{22}$. En el marco del afán jerarquizador que subyacía a las clasificaciones de la diversidad humana, circunstancias coyunturales como la derrota francesa frente a los prusianos en la guerra de 1870 no harían sino favorecer y alimentar la polémica sobre la rivalidad, capacidades y destinos divergentes de dos "razas»: la anglosajona (o germana) y la latina ${ }^{23}$.

En ningún lugar del mundo occidental esta visión dicotómica tenía proyecciones más palpables y hasta casi «medibles» que en el continente americano. Cierto es que en América la dicotomía «hispano" y "sajón" incorporaba también otro tipo de referencias raciales, ya que se consideraba a la primera una "raza mezclada» con elementos indígenas y africanos. Pero la matriz de significado no variaba, ya que se entendía que la resistencia a "cruzarse" con "razas inferiores" que habían practicado los anglosajones era un indicio más de su superioridad frente a los "hispanos". De hecho, ese convencimiento venía desempeñando un papel importante en las relaciones de los Estados Unidos con sus vecinos del sur, al ser utilizado por los primeros para legitimar acciones tales como la expansión de ese país sobre territorios mexicanos ${ }^{24}$.

21 Es decir, la relación, expresada en porcentaje, entre la anchura y la longitud del cráneo. Esta medida clasificatoria fue introducida en 1844 por ei anatomista sueco Anders Retzius.

${ }^{22}$ STEPAN, Nancy: The Idea of Race in Great Britain,"1800-1960, The MacMillan Press, London and Basingstoke, 1982, pág. 97. Horsman, Reginald: Race and Manifest Destiny. The Origins of American Racial Anglo-Saxonism, Harvard University Press, Cambridge (Mass.), 1981, págs. 7-78.

23 Tal como se demuestra en el libro de LiTVAK, Lily: Latinos y anglosajones: orígenes de una polémica, Puvill Editor, Barcelona, 1980.

24 Cfr. Horsman, ob.cit; JoHNSON, John J.: «The Racial Composition of Latin American Port Cities at Independence as seen by Foreign Travelers», Jahrbuch für Geschichte von Staat, Wirtschaft und Gesellschaft Lateinamerikas, 23 (1986), págs. 247-266; WAYNE, Philip Wayne: The Tree of Hate: Propaganda and Prejudices affecting the United States Relations with the Hispanic World, New York and London, 1971. 
En el extremo austral del continente, esta visión "racializada» de las diferencias entre el norte y el sur se fue haciendo cada vez más apreciable a medida que avanzaba la segunda mitad del siglo. Ejemplo de ello es el muy conocido y polémico Domingo Faustino Sarmiento, que se basó en esa misma perspectiva para hacer su libro Conflicto y armonias de las razas en América. publicado en $1883^{25}$. En esa obra Sarmiento explicaba los desarrollos tan disímiles de la América anglosajona y de la América hispana a partir de las diferencias cúlturo-raciales que existían entre ellas. Modificaba así, de forma radical, su interpretación de 1845 - la de su famoso Facundo-- que fundaba la dicotomía "civilización y barbarie" en los diferentes desarrollos institucionales de los pueblos. Mientras que en su obra de juventud Sarmiento no había citado ni una sola vez el concepto de «raza», en el libro de 1883 las diferencias raciales lo explicaban todo. Para el último cuarto del siglo xIX era ya un lugar común entre los hispanoamericanos utilizar las calegorías raciales para explicar los fracasos propios y los éxitos ajenos, evaluar las diferencias entre las "dos Américas" y hacer previsiones sobre sus respectivos destinos.

En tal contexto, no sorprende que la guerra hispano-norteamericana fuera comúnmente interpretada -tanto en Europa como en América- en clave de ese mismo enfrentamiento racial. La «consanguinidad" latina - que no la política de España en Cuba- llevaría a muchos franceses e italianos a alinearse con la primera ${ }^{26}$, al tiempo que la postura de Gran Bretaña sería vista como de "simpatía" hacia los Estados Unidos, inspirada no tanto por cuestiones estraté gicas y geopolíticas, sino por hallarse ambos paises «bound by ties of race ${ }^{27}$. De la misma manera, los medios de prensa sudamericanos, de cualquier tendencia, repetirian una y otra vez que la guerra entre Estados Unidos y España no era, "en el fondo, sino una manifestación del antagonismo que se observa entre la raza inglesa y la raza española dentro del continente americano" 28 .

Siguiendo la misma secuencia lógica, la guerra hispano-norteamericana y la evidente superioridad tecnológica de los Estados Unidos -que consagró en brevísimo lapso la victoria de sus armas frente a las españolas- se interpretaron en Europa como una señal más de la decadencia de las naciones latinas. Esa visión alimentó el pesimismo sobre el futuro de la "raza" y favoreció el abandono del ideal panlatino, que había tenido un gran desarrollo en las décadas anteriores ${ }^{29}$.

25 SARMIENTO, Domingo F.: Conflictos y Armonías de las Razas en América, T. XXXVII y XXXVIII de las Obras Completas de Sarmiento, Editorial Luz del Día, Buenos Aires, 1953.

26 Comentando la actitud mayoritaria de la prensa francesa ante la contienda, el representante británico en Paris observaba que «as might be expected, (they) take sides with Spain as to the merit of the dispute. Financial interests, as well as such consanguinity as exists between the Latin races, outweigh in this instance such political sympathy as might be supposed to exercise an influence in favour of Republican pretension». Monson a Salisbury, París, 13 de abrit de 3898, FO/1 15/1075.

27 Ibidem.

2* El Correo Español, Buenos Aires, 13 de mayo de 1898.

29 Véase LITVAK, ob.cit. págs. 20-48. Una de las caracteristicas del fin de siglo es la proliferación de libros dedicados a analizar esta supuesta decadencia, como los de Edmond Demolins: En quoi

Hispaniu, LVII/2, núm. 196 (1997) 589-609 
Ahora bien, en América del Sur $\rightarrow$ y esto es lo que interesa destacar-el 98 produjo el movimiento contrario. En efecto, la intervención norteamericana agudizó la conciencia étnico-cultural hispanoamericana y canalizó hacia una reformulación positiva, en el sentido de una afjrmación nacionalista, el debate en torno al destino de las dos razas rivales que parecía estar dirimiéndose en las aguas del Caribe. En otras palabras, la guerra hispano-norteamericana ayudó a cambiar el signo de la polémica, colocando "lo latino" en el polo positivo de la dicotomía.

\section{LA INVERSIÓN DE LAS DICOTOMÍAS}

Para explicar la inversión antes mencionada voy a recurrir a un texto que fue muy respetado en los últimos tramos del siglo pasado. Me refiero a $L a$ Lucha de Razas, del politólogo austríaco Luis Gumplowicz, publicado en la ciudad de Viena en 1883. Las ideas de profesor de Gratz que voy a comentar se inscriben en las propuestas teóricas que -como las de G. Le Bon o M.G. Lapouge- en los últimos tramos del siglo xix conducirían el debate sobre la diversidad humana hacia la consagración de la "raza" como la categoría explicativa primera y última de todos los procesos humanos.

En el libro de Gumplowicz se propone que existen tres maneras o teorías de concebir la historia o el desarrollo de la humanidad. La primera de estas teorías presenta la historia como la obra de una divinidad. Desde esta perspectiva todas las cuestiones de la existencia humana atañen a la voluntad y los designios del Ser Supremo, y todas las respuestas se buscan y se encuentran en la religión. La segunda teoría considera la historia y el desarrollo de la humanidad como la obra del espíritu humano libre. En este caso es la razón humana la que busca las vías que la humanidad debe seguir y los fines adonde debe dirigirse. Finalmente, la tercera teoría concibe a la humanidad como un elemento de la naturaleza, elemento que no es libre. Esta perspectiva busca las leyes naturales, merced a la cuales la humanidad recorre, en virtud de una eterna necesidad, los caminos naturales que le son prescritos ${ }^{30}$.

Obviamente, para Gumplowicz esta última perspectiva era la que correspondía a los espíritus más avanzados de la época y al porvenir, y era ella la que subyacía a su teoría de que el destino de la humanidad se rige por el combate permanentemente renovado entre las razas, combate cuyo resultado siempre es el mismo: el elemento étnico más poderoso prospera y después ejerce su dominación, cuya influencia es siempre y en todas partes civilizadora ${ }^{31}$.

consiste la supériorité des anglosaxons (París, 1897), G. Sergi: La decadenza delle nazioni latine (Turín, 1900) y Léon Bazalgette: A quoi tient l'infériorité française (Paris, 1900) y L'Avenir Latin (París, 1900).

30 GuMPLowicz, Luis: La lucha de razas, La España Moderna, Madrid, s/f., págs. 11-12.

3t Idem, pág. 462. 
Esta posibilidad de concebir la historia o el desarrollo de la humanidad desde perspectivas diferentes estuvo presente en los debates que se produjeron en torno a la guerra hispano-norteamericana. En esos debates nadie discutía el derecho de Cuba a la independencia, ni siquiera los sectores más conservadores, dentro y fuera de la colonia hispana. El eje de la discusión era España frente a Estados Unidos, latinos frente a anglosajones.

La percepción más generalizada sobre la intervención norteamericana en la guerra se enmarcó en la tercera teoría antes citada, que concebía la historia de la humanidad como sujeta a leyes irrevocables de la naturaleza. Esta visión consideraba inevitable el triunfo de los Estados Unidos, no sólo por su superioridad objetiva en tecnología, medios y recursos, sino porque en la dialéctica de la lucha de razas esa misma superioridad era indicio de que los Estados Unidos representaban el elemento destinado, por ley natural, a prosperar sobre sus contrincantes e imponer su influencia civilizadora; ya que, desde esta perspectiva, eran los más civilizados los que avanzaban en la conquista.

Esta visión es la que explica, por ejemplo, que en un artículo publicado en un periódico tan serio y progresista como La Nación de Buenos Aires (fundado y editado por el historiador y ex presidente Bartolomé Mitre) se desease éxito simultáneamente a los dos contendientes. Esta manifestación, que podría ser interpretada como oportunismo o como un caso extremo de escisión de la personalidad del autor, lo que estaba expresando en realidad era la conjunción de un deseo visceral - la victoria de España-y de una convicción -que las leyes de la naturaleza determinaban el triunfo de los Estados Unidos- ${ }^{32}$.

Pero no era ésta la única perspectiva desde la que se vela en la época el conflicto del 98. Hubo una interpretación contrapuesta que enmarcó la guerra hispano-norteamericana en la segunda teoría antes citada, la que percibía el desarrollo de la humanidad como la obra, no de las leyes naturales, sino de la razón humana, del espíritu humano libre. Fue posiblemente el argentino Roque Sáenz Peña quien mejor verbalizó esta interpretación, en una conferencia dictada el 2 de mayo de 1898 en el Teatro Victoria de Buenos Aires, con ocasión del acto antes mencionado que fuera convocado con motivo de la guerra hispano-norteamericana.

Sáenz Peña, que entre 1910 y 1916 sería elegido presidente de la República Argentina, era ya entonces un jurista conocido, con actuaciones que le habian dado prestigio en el ámbito latinoamericano. Fue él quien, con motivo de la Conferencia de Washington de 1890 que sentó las bases para la formación de la Union Panamericana, contrapuso a la famosa doctrina Monroe, de «América para los americanos», su desde entonces también famosa frase -al menos en América del Sur- de "América para la Humanidad» ${ }^{33}$.

32 Sobre las actitudes de La Nación ante el confjicto hispano-norteanericano véase la nota critica publicada en El Correo Español, Buenos Aires, 15 de mayo de 1898.

33 Es posible que la preocupación de Sáenz Peña por definir instrumentos legales de proyección internacional que condenasen e impidiesen las intervenciones de hecho, haya tenido su primera fuente de inspiración en la guerra del Pacifico (1879-1883), a la que acudió al frente de un batallón de voluntarios para defender los derechos del Penú frente al expansionismo chileno.

Hispunia, LVII/2, núm. 196 (1997) 589-609 
Ocho años más tarde, en 1898, Sáenz Peña defendió la postura de que la guerra de Cuba era una guerra civil, una "cuestión de familia", basándose para ello tanto en los vínculos de raza y linaje como en el hecho de que los cubanos tenían representación parlamentaria en la Península ${ }^{34}$. La acción norteamericana era, por tanto, una intervención extranjera, realizada por "ejércitos ajenos al litigio y al territorio, exóticos y extraños a la raza de los dos beligerantes». Más aún, se trataba de una intervención por la fuerza, la aplicación de un poder coercitivo y arbitrario, semejante al que utilizaron los papas y los emperadores. Y esto, según Sáenz Peña, conducía a los Estados Unidos atrás en el tiempo, les alejaba de los usos y prácticas del derecho moderno, que era el derecho universal de las naciones. Cuanto más se alejasen las prácticas internacionales del respeto a la libertad natural de las naciones, más se retrotraían sus protagonistas al estado de primitivismo y de barbarie ${ }^{35}$.

Esta forma de percibir la intervención norteamericana tiene dos proyecciones importantes. En primer lugar, como se ha dicho antes, en la primera Conferencia Panamericana de Washington de 1890 Sáenz Peña había rechazado expresamente la Doctrina Monroe, defendiendo a cambio la noción de "América para la Humanidad". En 1898, el mismo Sáenz Peña rechazaba la intervención norteamericana en nombre de la libertad de las naciones, que identificaba con el derecho universal, y asociaba este último con el avance de la civilización. Sólo cuatro años más tarde, en 1902, el gobierno argentino iba a proponer lo que habría de llamarse la Doctrina Drago, que buscaba consagrar el principio de la no intervención. La Doctrina Drago ${ }^{36}$ era la expresión, en forma de herramienta legal, de los principios que había enunciado Sáenz Peña cuatro años antes, con ocasión de la guerra hispano-norteamericana. Es decir, el 98 aparece así implicado en la definición de una herramienta ideológica que iba a tener un peso importante en el ámbito de las relaciones interamericanas a lo largo de una buena parte del siglo $\mathrm{xx}$.

Pero la perspectiva planteada por Sáenz Peña tenía una segunda proyección aún más significativa, porque precedía y englobaba a la anterior. En el efrentamiento hispano-norteamericano se atribura a España el papel de representante y depositaria del más alto producto de la civilización: el derecho universal, A la inversa, se consideraba que Estados Unidos actuaba por mera fuerza y representaba, por tanto, lo bárbaro y lo primitivo; en otras

34 Véase el discurso completo de Roque Sáenz Peña en El Correo Español, Buenos Aires, 3 de mayo de 1898.

35 Ibidem.

36 Por Luis Drago, entonces Ministro de Relaciones Exteriores de Argentina, quien enunció dicho principio en una nota enviada a los Estados Unidos en 1902. Esta doctrina sería defendida personalmente por Sáenz Peffa afios más tarde, con ocasión de la Conferencia de La Haya de 1907, en la que abogó por la solidaridad internacional y se manifestó enemigo de los «exclusivismos de raza». Puede hacerse el seguimiento de las posiciones de este personaje en materia de derecho internacional en SaEnz PeÑa, Roque: Escritos y Discursos, Peuser, Buenos Aires, 1914-1915 (2 tomos). 
palabras, el eventual triunfo de los Estados Unidos no se leía en clave del avance inexorable de la civilización, sino de crisis de la civilización ${ }^{37}$.

De tal forma, y como se ha dicho antes, mientras que en Europa la guerra hispano-norteamericana fortalecía la imagen de un supuesto proceso de decadencia de la raza latina frente al avance de su raza rival, en América del Sur ese mismo conflicto contribuía a invertir el signo de la polémica, al trasladarse lo latino (o hispano) al polo positivo de la dicotomía.

Para comprender hasta qué punto era significativo este proceso ideológico, es importante tener en cuenta que la mencionada inversión no estaba implícita en el rechazo a la intervención norteamericana y en el deseo de una eventual victoria de España. Una forma muy característica en la que también se expresó el apoyo a España es la que aparece, por ejemplo, en el periódico liberal El Vigia, de Bogotá. En un artículo que defiende las ideas progresistas y la independencia de Cuba, se afirma al propio tiempo que «el hecho de que (...) la barbarie, la corrupción y la anarquía se hayan colocado del lado de España, no nos impide rendir homenaje a la heroica nación y desear su victoria. Que Cuba sea libre, pero que España nunca perezca” ${ }^{38}$.

Ahora bien, desde una perspectiva de historia de las ideas importa que se haya producido ese traslado de lo latino (o hispánico) del polo negativo al positivo, porque esta inversión no es ni inocente, ni irrelevante. Recordemos que el siglo xix es moderno, no posmoderno; cree sin ambages en la marcha inexorable del progreso, lo que implica el convencimiento en un proceso lineal y ascendente donde lo bárbaro y lo primitivo ocupan los peldaños más bajos y deben ubicarse en el pasado, mientras que lo civilizado ocupa los peldaños más altos y debe ubicarse en el futuro.

Es precisamente esta inversión lo que permite la identificación de los Estados Unidos con Calibán, el caníbal shakespereano. Y por eso un producto directo de esta visión es Ariel, el famoso libro del uruguayo José Enrique Rodó aparecido en 1900, donde se hace la conocida contraposición entre Ariel y Calibán, entre el espíritu y la materia, entre la esencia latina y la esencia anglosajona, Hispanoamerica frente a Estados Unidos. Es bien sabido por testimonios de Rodó y de su entorno - como por ejemplo, de su amigo Manuel Ugarte, el gran propugnador de la unidad hispanoamericana- que el Ariel fue concebido en medio de las discusiones que rodearon a la guerra del 98. De hecho lo que hace Rodó es recoger, con gran calidad metafórica y literaria, un pensamiento que ya estaba en el aire e incluso se hallaba presente en las

37 Ver el discurso de Paul Groussac, pronunciado ef 2 de mayo de 1898 en el mismo evento de! Teatro de la Victoria de Buenos Aires. El Correo Español, Buenos Aires, 4 de mayo de 1898. Una forma exacerbada de esta línea interpretativa aparece en un artículo publicado en el mismo periódico el 27 de junio de 1898, que lleva por título «De cómo se puede demostrar cientificamente que los yanquis son los pieles rojas de los modernos pueblos americanos»; el autor basa su argumentación en un trabajo del filósofo francés Alfred Fouillée sobre «Los factores de los caracteres nacionales».

38 El Vigía, Bogotá, 27 de abril de 1898 . El representante británico en esa ciudad afirmaba que las posiciones defendidas por el periódico ante la guerra eran representativas de los sentimientos de la mayoría. Villiers a Salisbury, 5 de mayo de 1898 , FO/115/1076.

Hispania, LVIL/2, núm. 196 (1997) 589-609 
manifestaciones públicas de más de un personaje conocido. Fue precisamente en 1898, en un artículo publicado en una prestigiosa revista literaria de Caracas y en el que, no casualmente, se hacía referencia al acto del 2 de mayo del Teatro Victoria de Buenos Aires, cuando Rubén Darío se refirió por primera vez al "triunfo de Calibán" ${ }^{39}$. Símil que, por su parte, le había sido inspirado al nicaragüense por sus lecturas de Renan. Poco antes y en Buenos Aires, en el mismo acto en que habló Sáenz Peña y que iba a reseñar Darío, el historiador Paul Groussac manifestaba su cólera ante la intervención nortemericana con frases que surgen claramente del mismo clima de ideas que dos años más tarde aparecerían plasmadas en el Ariel ${ }^{40}$.

Pero esta inversión que coloca lo hispano en el polo positivo de la dicotomía no sólo implicaba la identificación de Estados Unidos con Calibán, sino también su contrario, es decir, la de Hispanoamérica con Ariel. Y esto introduce un matiz importante en las relaciones de amor-odio que los hispanoamericanos venían manteniendo a lo largo de todo el siglo con su antigua metrópoli, por un lado, y con la herencia cultural que ella les había legado, por otro. Porque lo que se plantea es que la raza latina, es decir, la raza hispana, puede alcanzar la meta del progreso siendo fiel a su propia esencia; o sea, sin seguir el camino de los modelos exitosos del XIX.

Se entenderá mejor este salto ideológico si recurrimos a un escrito que es en muchos sentidos precursor del Ariel, pero que vio la luz treinta y cinco años antes, en 1865. Debido a la pluma del chileno Francisco Bilbao, se discuten en él los vicios, virtudes y potencialidades de las dos razas rivales que, en el territorio americano, se disputaban «la soberanía territorial y el imperio del porvenir" ${ }^{41}$. Como todos sus contemporáneos, Bilbao admiraba el "modelo» de los Estados Unidos del norte, que consideraba no sólo valioso, sino el único cuyos principios políticos podían constituir la base para alcanzar la meta final de la humanidad que era, en palabras de Bilbao, «la asociación de las personalidades libres, hombres y pueblos, para conseguir la fraternidad universal» ${ }^{42}$. Pero el chileno observaba también, con aprensión, que el país que había elaborado ese mismo modelo era el que amenazaba la libertad y la integridad de los estados hispanoamericanos ${ }^{43}$. Bilbao veía en esto una contradicción que le llevó a pensar que el modelo norteamericano no podía trasladarse al sur sin una previa adaptación a las condiciones propias de los sudamericanos, que en

39 Dario, Rubén: «El triunfo de Calibán», en El Cojo /lustrado, Caracas, I de octubre de 1898, pág. 676 .

40 El Correo Español, Buenos Aires, 4 de mayo de 1898.

4 BILBAo, Francisco: "El Congreso normal americano», en Klem: El Evangelio Americano, Biblioteca Ayacucho, Caracas, págs. 273-289.

42 Cff. RolG, Arturo Andrés: «Los ideales bolivarianos y la propuesta de una Universidad Latinoamericana Continental", Ideas en Torno de Lahinoamérica, Universidad Nacional Autónoma de México/Unión de Universidades de América Latina, México 1986, Volumen 1, págs. 71-83.

43 Bilbao escribía bajo ef influjo de episodios tales como la incursión en Centroamérica del aventurero norteamericano - llamado por sus contemporáneos el «filibustero»— William Walker, asi como la expansión norteamericana sobre territorios mexicanos.

Hispaniu, LVII/2, núm. 196 (1997) 589-609 
algunos aspectos consideraba superiores a las de sus vecinos del norte: «No nos creemos tan desnudos de obras morales - afirmaba Bilbao- de modo que nuestra pequeñez nos desanime. Conocemos las glorias y aun la superioridad del Norte, pero también nosotros tenemos algo que colocar en la balanza de la justicia». Y añadía: "Preferimos lo social a lo individual, la belleza a la riqueza, la filosofía a los textos, el arte al comercio, la poesía a la industria, el espíritu al puro cálculo, el deber al interés.... ${ }^{44}$..

Esta visión que contraponía una América anglosajona pragmática y materialista a una América hispana esteticista y espiritualista iba a reaparecer varias décadas más tarde en la obra de Rodó. Pero había una diferencia fundamental entre ambas: para el chileno ese bagaje positivo constituía lo que los hispanoamericanos podían poner en la balanza de los méritos, para adaptar $\mathrm{y}$ "mejorar" el modelo de los americanos anglosajones, imprimiéndole un perfil más "espiritual» y acorde a las características propias de Hispanoamérica. Pero jamás se le hubiera ocurrido a Bilbao proponer una visión dicotómica en la que los Estados Unidos ocuparan el polo negativo.

Esta diferencia es precisamente el eje vertebrador del pensamiento de fin de siglo, en el que el 98 no actúa tanto de generador (como suele afirmarse) sino de catalizador: ya no se trataba de adoptar un modelo ajeno, ni siquiera ajustándolo a las condiciones propias. Se trataba de que era posible crear un modelo propio sobre la base de las propias «esencias», a partir de considerar que estas esencias no sólo no se oponían a la construcción de la modernidad, sino que eran en sí mismas matrix de civilización. Esto es lo que subyace al Modernismo, ese movimiento caracerístico del fin de siglo hispanoamericano, dos de cuyos principales representantes fueron, precisamente, Rubén Darío y José Enrique Rodó. El Modernismo, que sería trasladado a España con gran éxito, fundamentaba la búsqueda de la modernidad -es decir, el proyecto colectivo de futuro- en la tradición y en las raíces.

De tal manera en América -esa porción del mundo occidental donde las diferencias entre las dos "razas" rivales parecían encarnarse de la forma más conflictiva y palpable- la racialización extrema del discurso en torno a la guerra del 98 favoreció el desarrollo de un marcado esencialismo cultural, basado en la recuperación de la esencia hispana -y éste es el matiz que interesa destacar-como matriz de civilización, capaz de todos los progresos y de todos los logros.

Por añadidura este proceso ideológico (reforzado - que no provocadopor el resultado de la guerra, que consagró el final de los últimos enclaves coloniales de España en América) se produjo en un momento particularmente propicio, cuando las élites hispanoamericanas estaban asumiendo como imperativo de sus respectivas construcciones nacionales la búsqueda de cohesión interna mediante la homogenización de sus sociedades, tanto en términos simbólicos como étnico-raciales ${ }^{45}$.

44 Idem y Bilbao, Francisco: «El Congreso normal americano», ob.cit.

45 Mediante la intervención activa del Estado, se esperaba convertir a unos conglomerados heterogéneos en auténticas «naciones» homogéneas e internamente cohesionadas. Es la época en 


\section{LA PROYECCIÓN DEL 98 EN EL IMAGINARIO DEL NUEVO SIGLO}

No parece casual, por ejemplo, que a partir del 98 la apropiación de la raíz hispánica en los mitos de origen sudamericanos aparezca formulada en términos que se alejaban de la tradicional polémica decimonónica sobre las bondades o maldades de la colonia, o sobre si el origen estaba en lo prehispánico o en lo hispánico. En estas nuevas elaboraciones, fruto de personajes tan significativos como Ricardo Rojas en la Argentina o Nicolás Palacio en Chile, hay una voluntad de detectar las «esencias raigales» de la nacionalidad en el aporte remotísimo de la raza ibera o visigoda ${ }^{46}$.

Es sabido que en Europa la búsqueda de los orígenes nacionales en las poblaciones prerromanas o en el aporte indoeuropeo fue una característica de las construcciones históricas desde las primeras décadas del siglo $\mathrm{xIX}{ }^{47}$. Por otra parte, en la mentalidad decimonónica los orígenes determinaban las potencialidades, o no, de una raza, de un cultura, de una nación, para alcanzar las más altas cotas del progreso. Por todo ello es significativo que en Sudamérica sólo a comienzos del siglo $\mathrm{xx}$-es decir, con posterioridad al 98 - se encuentren elaboraciones sobre las "esencias" godas o iberas; tanto más aún cuando este tipo de desarrollos ideológicos apareció sobre todo en países como Argentina y Chile, que tenían una visión de «Destino Manifieston y que tendían $-\mathrm{y}$ tienden aún-a afirmar de forma excluyente el carácter europeo de sus cornponentes culturales. En el caso argentino, además, lo anterior se articula en un proceso muy particular: es precisamente a finales del xIX y principios del xx cuando el imaginario nacional, mediante una pirueta ideológica notable y que nunca ha recibido la atención que se merece, niega y acaba olvidando la presencia en su suelo de componentes de origen indígena o africano para autoproclamarse una nación de "raza blanca"; convirtiendo además esta supuesta "uniformización por blanqueamienton en un referente afirmativo de identidad nacional.

Por otra parte, la reivindicación de la esencia cultural hispánica a partir de la inversión que coloca lo hispánico en el polo positivo de la dicoto-

que se habla de que una nación sólo puede ser grande si tiene ideales, y sólo puede tener ideales si la población que la integra responde a unos mismos estímulos que resisenen en una única «alma» colectiva. Cfr. Quijada, Mónica: «La nación reformulada. México, Perú, Argentina, 1900-1930» en Antonio Annino, Luis Castro Leiva y François-Xavier Guerra (eds.): De los Imperios a las Naciones. Ibeoramérica, Ediciones lbercaja, Zaragoza, 1994, págs. 567-590; Id: "¿Qué nación? Dinámicas y dicotomías de la nación en el imaginario hispanoamericano del siglo XIXn, en F.-X. Guerra y Mónica Quijada (coords.): Imaginar la Nación. Número monográfico de los Cuadernos de Historia Latinoamericana, AHILA, Münster, Hamburg, No.2, 1994, págs. 15-51.

46 Cfr. Ricardo Rojas: Retablo Español, Volumen 25 de las Obras Completas de Ricardo Rojas, Editorial Losada, 1948; Nicolás Palacios: Raza chilena, Editorial Chilena, Santiago de Chile, 1918. Sobre la exaltación de la «raza ibérica» frente a la «jndogermana» véase también Antonio Rodríguez del Busto: Peligros americanos. Crítica de la Ciencia Política, Buenos Aires, I 899 y Color y lenguaje, Buenos Aires, s/f.

47 Como es el caso de Michelet en Francia o de Modesto Lafuente en España, por nombrar dos entre muchos.

Hinparia, LVIV/2, núm. 196 (1997) 589-609 
mía - proceso que, como hemos visto, se produjo en relación con el 98se articula también en un fenómeno muy especial de finales del XIx y primeras décadas del xx. Me refiero al fortalecimiento de las tendencias unitarias hispanoamericanistas. Este fenómeno, que no es más que otra forma de nacionalismo ${ }^{48}$, se produjo de una manera un poco distinta a la que se suele presentar cuando se dice que el 98 , al eliminar la última barrera de suspicacia entre España y sus antiguas colonias, permitió la irrupción de las tendencias hispanoamericanistas y la recuperación del pasado hispánico. Esto no es totalmente exacto.

La tendencia a la revalorización de la colonia y la expansión de las ideas hispanoamericanistas no surgió con el 98 . Se venía produciendo desde tiempo atrás y el 98 sólo vino a confirmar y consolidar esa tendencia. No está de más recordar la agilización en las relaciones entre el mundo intelectual español e hispanoamericano que se produce en torno a 1892, en el cuarto centenario del Descubrimiento de América, y las múltiples expresiones de revalorización del pasado colonial que tomaron forma entonces ${ }^{49}$. Fenómeno que, por otra parte, recoge tendencias anteriores. En la Argentina, por ejemplo, es importante recordar que Alberdi y Sarmiento, los dos grandes ideblogos que favorecieron la idea de que todo lo español, incluida la lengua, debía borrarse del acerbo cultural e histórico sudamericano, en los últimos años de su vida corrigieron esta visión. $\mathrm{Y}$ estos dos personajes --cuyas opiniones no deben ser vistas de forma puramente individual, sino como expresiones cualificadas de las tendencias de la época- murieron uno en 1884 y el otro en 1885, es decir; años antes de los fastos del cuarto centenario y de la guerra hispano-norteamericana.

Pero el 98 y lo que he llamado la traslación de lo hispánico al polo positivo de la dictomía contribuyó a que la expresión de esas tendencias asumiera un marcado esencialismo cultural, que no estaba presente en la recuperación hispánica de Alberdi o Sarmiento. En otras palabras, la inversión mencionada favoreció la imposición del modelo herderiano que clarísimamente subyace a las manifestaciones más importantes del hispanoamericanismo de principios del siglo xx, como por ejemplo las propuestas del ideólogo argentino Manuel Ugarte, cuyos planteamientos sobre lo que él llamaría «La Nación Latinoa-

48 El hispanoamericanismo no entró en competencia ideológica con los nacionalismos «estataless. Por el contrario, se trató de un movimiento de teafirmación colectiva en cl que lo nacional se reforzaba con lo pannacional, y viceversa. Por ello lo considero una suerte de «nacionalismo supraestatal». Cfi: QuiJADA, Mónica: «La Nación reformulada: México, Perú, Argentina (1900-1930)», ob.cil. Ver esp. págs. $587-8$.

49 Cfr. Leoncio López-Ocón: «Las actividades americanistas del naturalista español Jiménez de la Espada (1831-1898)", en A.R. Diez Torres et al., (coords.): La ciencia española en ultramar, Madrid, Doce Calles, 1991, págs.363-380; Id: "Las relaciones científicas entre España y la América Latina en la segunda mitad del siglo xIx: Un balance historiográfico», en Revista de Indias, 50 , No.188 (enero-abriI 1990), págs.305-333; Salvador Bernabéu Albert: El IV Centenario del Descli. brimiento de Anérica en España, CSIC, Madrid, 1987.

Hixpentitt. LVIV/2, núm. 196 (1997) 589-609 
mericanan tomaron forma, lo mismo que el Ariel, en medio de las emociones que produjo la guerra hispano-norteamericana ${ }^{50}$.

Todo este proceso permitió a su vez otro desarrollo ideológico; la revalorización de la imagen de España por la nueva generación de la élite intelectual hispanoamericana, pero eso sí: desde una perspectiva muy distinta a la sustentada por los hispanoamericanistas peninsulares. Mientras estos últimos - como Rafael Altamira, por ejemplo- veían en su país al intermediario natural entre el espíritu europeo y las necesidades culturales de los jóvenes pueblos americanos ${ }^{51}$, los sudamericanos verían en España al depositario original de las esencias culturales comunes. Por eso varios de ellos van a viajar a España, y van a recomendar que se estudie a España, su historia, su cultura, porque se trata de la propia historia y de la propia cultura. Pero dejan muy clara una cuestión: no es lo mismo la esencia cultural hispana, que a todos pertenece -y que el proceso ideológico en torno al 98 ha contribuido a colocar en el nivel más alto de las potencialidades para la civilización-que la España que les era contemporánea, país anquilosado y muy necesitado de las energías nuevas que sólo el contacto con Hispanoamérica podía insuflar en sus envejecidas estrticturas ${ }^{52}$. No casualmente la Argentina - que desde los años ochenta aspiraba a convertirse en "Los Estados Unidos

50 No casualmente Ugarte, que tuvo una gran influencia en toda Hispanoamérica en las primeras décadas del siglo $\mathrm{xx}$, tomó como modelo político para su propuesta de unidad nacional latinoamericana a la unificación alemana realizada por Bismarck unos an̆os antes. Es el mismo modelo que utilizaria el presidente argentino Juan Domingo Perón para su politica interior y exterior cuarenta años más tarde. UGarte, Manuel: El porvenir de la América Española, Prometeo, Valencia, 19 10; Id.: La Nación Latinoamericana, Ayacucho, Caracas, 1918; QuisADA, Mónica: "Zollverein e integración sudamericana en la política exterior peronista, 1946-1955. Análisis de un caso de nacionalismo hispanoamericanistaw, Jahrbuch für Geschichte won Staat, Wirtschaft und Gesellschaft Lateinamerikas (Köln), Vol.30, 1993, págs.1-38.

51 Sobre el Hispanoamericanismo peninsular véase Antonio Niño Rodríguez: «Hispanoamericanismo, regeneración y defensa del prestigio nacional (1898-1931)", en Pedro Pérez Herrero y Nuria Tabanera (coords.): España/Anérica Latina: un siglo de politicas culturales, Aicti/Sintesis, Madrid, 1993; Isidro Sepúlveda Muñoz: Comunidad culural e hispano-americanismo, 1885-1936, Universidad Nacional de Educación a Distancia, Madrid, 1994. Para una perspectiva previa a los procesos finiseculares, véase Leoncio López-Ocón: Biografía de "La América". Una crónica hispano-americana del liberalismo democrático español (1857-1886), Colección Tierra Nucva e Cielo Nuevo, CSiC, Madrid, 1987, así como los artículos de este autor citados en nota 49 supra. Un panorama particularmente lúcido sobte las imágenes respectivas acuñadas por España y los paises hispanoamericanos a lo largo de un siglo y medio es el trabajo de HALPER DONGHI, Tulio: «España e Hispanoamérica: miradas a través del Atlántico (1825-1975)m, en $/ d$. El Espejo de la Historia. Problemas argentinos y perspectivas latinoamericanas, Editorial Sudamericana, Buenos Aircs, 1987, págs. 65-110.

${ }_{52}$ Cfr. GÁlvEz, Manuel: El solar de la raza, Biblioteca Calleja, Madrid, s/f; Kl: El Diario de Gabriel Quiroga, Anoldo Moen y Hno. Eds., Buenos Aires, 1910; RoJAs, Ricardo: La Restauración Nacionalista, Ministerio de Justicia e Instrucción Pública, Buenos Aires, 1909; ld.: El Retablo español, ob.cit.; PAYA, Carlos y CARDENAS, Eduardo: El primer nacionalismo argenimo en Manuel Gálvez y Ricardo Rojas, Peña Lillo, Buenos Aires, 1978; QUIJADA, Mónica: Mantel Gálvez: 60 años de pensamiento nacionalista, Centro Editor de América Latina, Buenos Aires, 1985. 
de América del Sur»- en el fin de siglo y en los años posteriores al 98 sería vista, por propios y ajenos, como el «bastión del latinismo frente al anglosajonismon 53 .

\section{EPf́LGo}

A la luz de lo expuesto hasta aquí, se hace difícil seguir afirmando que el 98 haya actuado en Hispanoamérica como una "divisoria de aguas", como un «antes y un despues». Prácticamente ninguno de los fenómenos cuyo origen se atribuye al 98 surgió en ese momento: ni la revalorización del pasado colonial, ni el temor al expansionismo norteamericano, ni las corrientes unitarias hispanoamericanistas. Todas estas tendencias son rastreables en las décadas anteriores al fin de siglo.

Tampoco puede decirse que el 98 pusiera fin de una vez y para siempre a las suspicacias entre España y sus antiguas colonias, pues estas suspicacias volverían a presentarse en el futuro en el marco de situaciones extremas, como la segunda guerra mundial. Ni siquiera en el ámbito de las relaciones oficiales tuvo incidencia inmediata la guerra hispano-norteamericana. Es significativo en este sentido que haya que esperar casi veinte años - hasta 1917- para encontrar la apertura de la primera embajada española en un país de la región, en este caso la Argentina.

Sin embargo, como hemos visto en páginas anteriores, el 98 aparece implicado en un conjunto de proyecciones ideológicas que tuvieron incidencia sobre el imaginario colectivo de las poblaciones sudamericanas.

Lo que subyace a esta aparente contradicción es que no fue la guerra misma lo que hizo posible esa incidencia, sino la dicotomfa "racial" que articuló simbólicamente el enfrentamiento entre los dos contendientes y favoreció la implicación en el mismo de muchos sudamericanos a partir de su autorreconocimiento como "raza hispana». Asimismo, en el marco de las reacciones de rechazo que suscitó la intervención norteamericana en un ámbito de sociabilidad pública bastante amplio, la capacidad de convocatoria del discurso fundado en esa dicotomía racial favoreció una reformulación simbólica -en un sentido de afirmación positivadora y esencialista - acerca de las potencialidades del elemento hispánico y de su capacidad intrínseca para generar un modelo de progreso. Modelo que no implicaba a España como país, sino a la "esencia hispánica" como referente cultural.

$\$ 3$ Sobre la Argentina como bastión del latinismo, véase Litvak, ob.cit., pág. 76 y ss. En cuanto a la aspiración a convertirse en los Estados Unidos de América del Sur (que por cierto, habia sido expresada por el propio Sarmiento en Conflictos y Amtonías..., ob.cit.) mereció un crítica del propio Rodó en el Ariel que, curiosamente y hasta donde llegan mis conocimientos, nunca ha sido comentada por la historiografia. Véase José Enrique Rodó: Ariel, Austral, Espasa-Caspe, Madrid, 1975, págs. 139-140.

Hispatia. LVII/2, mum. 196 (1997) 589.609 
El resultado de la guerra, que consagró el final de los últimos enclaves coloniales de España en América, reforzaría ese proceso ideológico, dando un sentido divergente a sus proyecciones a uno y otro lado del Atlántico. Mientras que a muchos españoles «les dolía España», a numerosos sudamericanos «dejaban de dolerles» su referentes culturales hispánicos. 